\title{
Experience with Miniaturized Cardiopulmonary Bypass in Cardiac Surgery: A Prospective Comparison of the NovoSCI Ready System to Off-Pump and Conventional Coronary Artery Bypass Grafting
}

\author{
Dominic Emerson ${ }^{1,2}$, Debbie Baldwin ${ }^{*}$, Miguel Pinales1, Michael Greenberg1, \\ Melissa Mattes' ${ }^{1}$ Gregory Trachiotis ${ }^{1,3}$ \\ ${ }^{1}$ Veterans Affairs Medical Center, Washington, DC, USA \\ ${ }^{2}$ Georgetown University Hospital, Washington, DC, USA \\ ${ }^{3}$ The George Washington University Hospital, Washington, DC, USA \\ Email: "gtrachiotis@mfa.gwu.edu
}

Received 20 October 2014; revised 13 November 2014; accepted 17 December 2014

Copyright (C) 2014 by authors and Scientific Research Publishing Inc.

This work is licensed under the Creative Commons Attribution International License (CC BY). http://creativecommons.org/licenses/by/4.0/

(c) (7) Open Access

\section{Abstract}

The major source of morbidity following cardiopulmonary bypass (CPB) is the systemic inflammatory response (SIRS response) which leads to multiple derangements in different organ systems. To combat this, miniaturized cardiopulmonary bypass circuits (MCPBC) have been created to lessen the inflammatory response to CPB. Here we examine early outcomes following coronary artery bypass grafting (CABG) using a MCPBC system compared to conventional bypass techniques at a single institution. Methods: 60 consecutive patients undergoing elective CABG were prospectively enrolled. Nine patients underwent coronary artery bypass grafting (CABG) with conventional CPB (cCABG), 33 underwent off-pump CABG (OPCAB), and the remaining 18 patients underwent CABG with a MCPBC system. Demographics and outcomes were compared between groups and statistical analyses applied. Results: No significant difference was observed in mortality between groups, with only one death reported in total. Morbidity was also low, totaling only $6.7 \%$, with none occurring in the MCPBC group. The MCPBC group required less PRBC and total blood product transfusion than the cCABG and OPCABG groups $(p=0.05)$, but changes in PLT and Hct over time were not different between groups. Conclusions: The MCPBC system was shown to be comparable to conventional bypass and OPCABG in terms of postoperative complications and mortality. Furthermore, the MCPBC system had the advantage of a decreased transfusion requirement. Based on

${ }^{*}$ Corresponding author.

How to cite this paper: Emerson, D., et al. (2014) Experience with Miniaturized Cardiopulmonary Bypass in Cardiac Surgery: A Prospective Comparison of the NovoSCl Ready System to Off-Pump and Conventional Coronary Artery Bypass Grafting. World Journal of Cardiovascular Surgery, 4, 232-238. http://dx.doi.org/10.4236/wjcs.2014.412034 
our preliminary observations, this mini-cardiopulmonary bypass circuit provides a safe alternative to conventional bypass techniques.

\author{
Keywords
}

\author{
Miniaturized Circuits, Coronary Artery Bypass Graft, Outcomes
}

\title{
1. Introduction
}

The development of cardiopulmonary bypass machines (CPB) in the 1950's revolutionized the field of cardiac surgery [1], and for the first time allowed surgeons to directly address intracardiac disease processes. Today, coronary artery revascularization (CABG) can be performed with a mortality rate less than $3 \%$ [2] [3], using the gold-standard technique of CABG with extracorporeal bypass. However, despite these good outcomes, CABG procedures still have significant morbidities associated with them including bleeding, thromboembolic events, arrhythmias, neurological insults, and renal and hepatic dysfunction [4]-[6]. Many of these events occur as a direct result of the systemic inflammatory response syndrome (SIRS) that is caused by the use of CPB [7].

In an effort to reduce the negative effects of $\mathrm{CPB}$, many strategies and concepts have evolved in the recent years, including the development of off-pump coronary bypass (OPCABG) to remove CPB from the procedure completely. However, OPCABG has its own limitations, primarily hemodynamic instability during surgery, technical difficulty, and long-term graft patency remaining a subject of debate. As a result, less than $25 \%$ of all CABG procedures are currently performed off-pump [8].

Another strategy to reduce the deleterious effects of CPB has been the development of minimized circuits [9]-[14]. The goal of these mini-cardiopulmonary bypass circuits (MCPBC) has been to minimize the contact between blood and foreign material, as this contact has been proposed as the inciting event that triggers much of the SIRS in the patient. MCPBC are closed circuit devices that serve the same purpose as traditional CPB, with several important changes. MCPBCs have no open venous reservoir to eliminate air-blood contact, reduced tubing length to lower required priming volume, heparinized tubing, and, perhaps most importantly, cardiotomy suction is eliminated. Here we seek to evaluate the potential advantages of the MCPBC system compared to conventional CPB and OPCABG at a single Veteran's Affairs hospital.

\section{Materials and Methods}

We prospectively enrolled 72 patients undergoing cardiac surgery after written informed consent was obtained. This group included 12 patients undergoing valve repair/replacement (9 Aortic, 2 Mitral, 1 Tricuspid), which were not included for analysis here but are discussed further below. In total, 60 patients underwent isolated elective coronary artery revascularization, and all were included in analysis. Nine patients underwent CABG using conventional cardiopulmonary bypass (cCABG), with 4 receiving a beating heart on-pump procedure (BHOP). Thirty-three underwent off-pump coronary bypass grafting (OPCAB) using our standard technique. The remaining 18 patients had CABG using a miniaturized extracorporeal circuit (MCPBC), of which 11 had the procedure performed with full cardiac arrest and 7 received BHOP procedures.

\subsection{Mini Pump Circuit Description}

We utilized the NovoSci Ready System 200, a closed loop extracorporeal system containing the Jostra RotaFlow centrifugal pump (Eresing, Germany). This system has a Jostra arterial filter, a Quadrox (Maquet, Germany) oxygenator, and a closed bag reservoir (Figure 1). Priming volume of the system is $1000 \mathrm{ml}$; however, by using a retrograde autologous prime (RAP) [15] this is decreased to 500 - $600 \mathrm{ml}$. The RotaFlow system features integrated level and bubble sensors for added safety (Figure 1). Blood from the surgical field was collected in a cell-saving device, but no cardiotomy suction was utilized.

\subsection{Conventional Circuit Description}

The cCABG circuit used was a Stockert S5 system with a Stockert 3T heater/cooler system (Sorin group; Arva- 

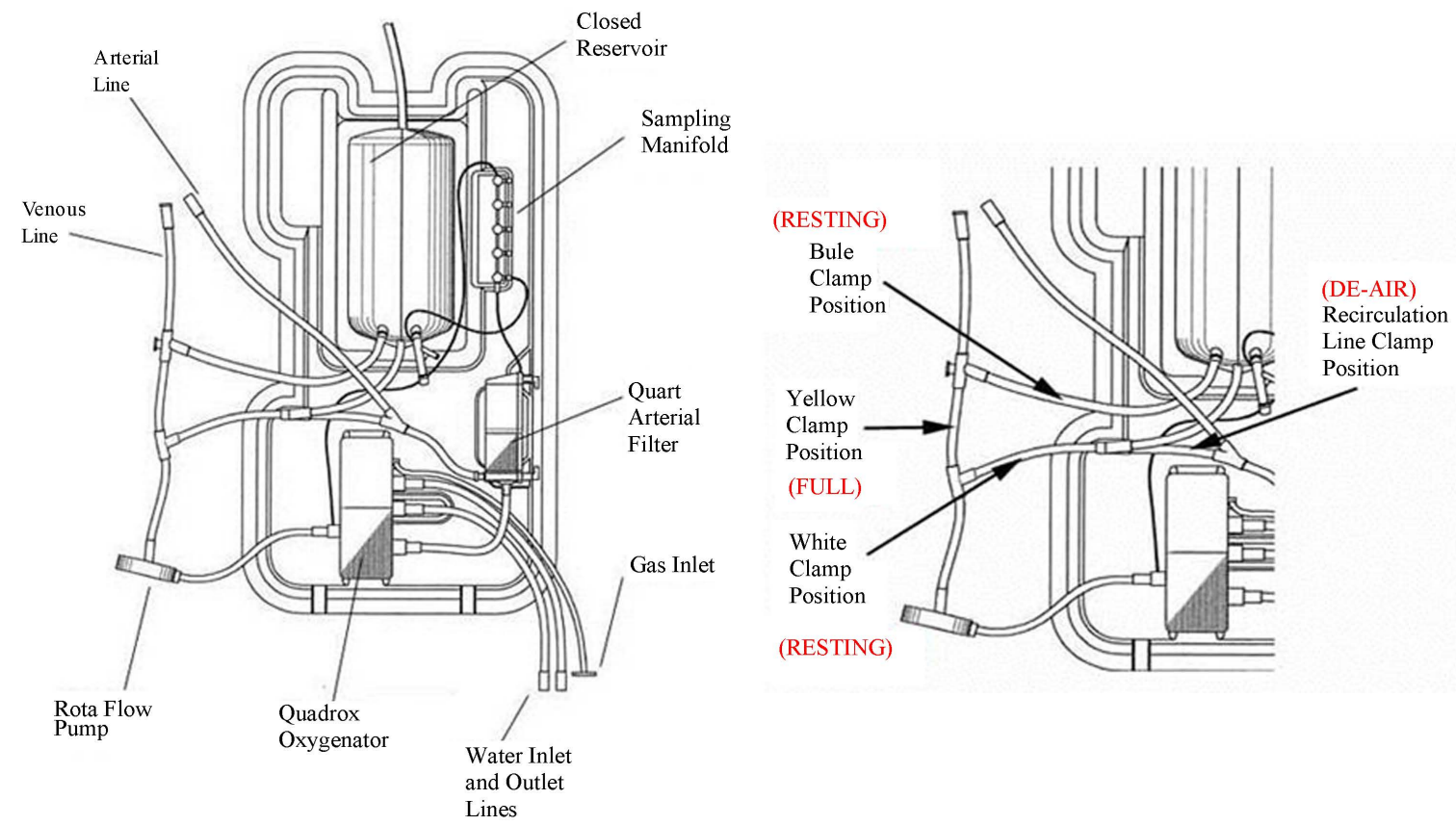

Figure 1. Diagram of the novosci ready system 200.

da, CO), which was set up and run in a conventional fashion. This has been our standard approach and system for some time. The priming volume is approximately $1700 \mathrm{ml}$ for this system.

\subsection{Statistical Analysis}

To compare groups, the Chi-square test was used for categorical data and a t-test was used for continuous data. Generalized Estimating Equation (GEE) models were used to examine the effect of pump types on within-subject change of HCT and PLT over time (preoperative and postoperative), corrected for the covariates sex, age, BMI, smoker, renal failure, and HTN; all other data is uncorrected. A p value of $<0.05$ was considered statistically significant throughout. Analyses were performed using SAS software (SAS Institute Inc., Minneapolis, $\mathrm{MN}$ ) with the assistance of our in-house statistician.

\section{Results}

Demographic data and pre-operative risk factors were similar between all three groups, with the exception of renal dysfunction which was more common in the off-pump group (Table 1).

The cross-clamp time and duration of cardiopulmonary bypass were not statistically different between the CCABG and MCPBC groups, nor was the use of the Cell Saver, though this was used less in OPCABG cases (Table 2).

Patients in the MCPBC group were transfused fewer packed red blood cells (PRBC) than the patients in the CCABG or OPCABG groups (0.4 v. 2.9 and 1.0 units, respectively, $\mathrm{p}=0.05)$. Transfusion of other blood products, fresh frozen plasma (FFP) and platelets (PLT), were also less within the MCPBC group as compared to the cCABG and OPCABG groups (FFP-0 vs. 1.3 and 0.18 ; PLT-0 vs. 0.11 and 0.06 , respectively), though this was not statistically significant (Table 2). Despite the differences in amount of transfusions between groups, the changes in the PLT and Hct over time (preoperatively v. postoperatively), as examined using GEE modeling, were not found to be significantly different among the groups ( $\mathrm{p}>0.1$ for both PLT and Hct).

Length of stay was shortest in the MCPBC group, but this was not statistically significant (cCABG-11.9, MCPBC-6.8, OPCABG-10.4 days, $p=0.492$ ). The overall rate of composite morbidity (including death, perioperative MI, new renal failure, mediastinits, cardiac arrest, reoperation for bleeding, prolonged ventilation, new CVA, or coma) was very low, with a total of four patients (6.7\%) suffering any morbidity, and only one death $(1.7 \%)$. None of the patients in the MCPBC group developed a morbidity, and three in the OPCABG and one in 
Table 1. Demographics.

\begin{tabular}{ccccc}
\hline & Conventional $(\mathrm{n}=9)$ & Novosci $(\mathrm{n}=18)$ & Off pump $(\mathrm{n}=33)$ & $\mathrm{p}$ \\
\hline Age $(\mathrm{y})$ & $63.3( \pm 4.5)$ & $62.4( \pm 9.9)$ & $65.2( \pm 9.4)$ & 0.550 \\
BMI $\left(\mathrm{kg} / \mathrm{m}^{2}\right)$ & $28.5( \pm 1.8)$ & $28.4( \pm 5.4)$ & $29.0( \pm 5.4)$ & 0.923 \\
CVD & $11 \%(1)$ & $17 \%(3)$ & $5 \%(6)$ & 0.822 \\
DM & $56 \%(5)$ & $44 \%(8)$ & $88 \%(29)$ & 0.834 \\
HTN & $100 \%(9)$ & $94 \%(17)$ & $15 \%(5)$ & 0.445 \\
IABP & $11 \%(1)$ & $0 \%(0)$ & $24 \%(8)$ & 0.225 \\
LAD $>$ 50\% & $22 \%(2)$ & $28 \%(5)$ & $6 \%(2)$ & 0.941 \\
Prior CABG & $0 \%(0)$ & $0 \%(0)$ & $30 \%(10)$ & $\mathbf{0 . 0 1 0}$ \\
Renal failure & $0 \%(0)$ & $0 \%(0)$ & $76 \%(25)$ & 0.277 \\
Smoker & $78 \%(7)$ & $56 \%(10)$ & $46.7( \pm 12.7 ; \mathrm{n}=32)$ & 0.870 \\
\hline
\end{tabular}

Table 2. Operative data and outcomes.

\begin{tabular}{|c|c|c|c|c|}
\hline & Conventional $(\mathrm{n}=9$ ) & Novosci $(n=18)$ & Off pump $(n=33)$ & $\mathrm{p}$ \\
\hline Cell saver used & $78 \%(7)$ & $56 \%(10)$ & $3 \%(1)$ & $<0.0001$ \\
\hline Pump time (min) & $90.1( \pm 45.0)$ & $93.4( \pm 22.0)$ & N/A & 0.80 \\
\hline Total PRBC (units) & $2.9( \pm 5.0)$ & $0.4( \pm 0.9)$ & $1.0( \pm 1.9)$ & 0.05 \\
\hline Total FFP (units) & $1.3( \pm 4.0)$ & $0( \pm 0)$ & $0.18( \pm 1.0)$ & 0.14 \\
\hline Total PLT (units) & $0.11( \pm 0.3)$ & $0( \pm 0)$ & $0.06( \pm 0.4)$ & 0.61 \\
\hline Total product (units) & $4.3( \pm 8.2)$ & $0.4( \pm 0.9)$ & $1.24( \pm 3.1)$ & 0.05 \\
\hline Hct change & $-3.7( \pm 5.6)$ & $-6.8( \pm 5.0)$ & $-4.8( \pm 4.2)$ & 0.194 \\
\hline PLT change & $-16.6( \pm 43.9)$ & $-35.6( \pm 46.0)$ & $-14.4( \pm 37.3)$ & 0.208 \\
\hline Death & $0 \%$ & $0 \%$ & $3 \%(1)$ & ns \\
\hline Composite morbidity & $11 \%(1)$ & $0 \%$ & $12 \%(3)$ & 0.46 \\
\hline
\end{tabular}

${ }^{* * *}$ Note-Data are presented as average ( + or - standard deviation), percentage of patients (actual number of patients), or average change $(+$ or - standard devation), as appropriate.

the cCABG groups did; however, due to the low overall number, this was not statistically significant ( $=0.458)$. Due to the very low mortality rate (one death), further statistical analysis of mortality was not undertaken.

\section{Discussion}

Conventional cardiopulmonary bypass continues to provide the best technical conditions for the cardiac surgeon, but this bloodless, motionless field comes at the cost of additional morbidities related to the SIRS response [4]-[7]. Off-pump CABG has been established as an alternative to conventional bypass; however, the technical challenges have limited adoption, as have questions regarding long-term patency rates. Consequently, less than 25\% of all CABGs are currently performed off-pump [8].

To address SIRS-associated conventional CPB morbidities, the miniaturized circuit has been introduced. The main advantage of the MCPBC system is reduction of the blood-foreign surface contact, which is believed to be the main culprit in activation of the complement cascade and cytokine production leading to a SIRS response [16]-[18]. Additionally, these circuits utilize heparin-coated tubing, which has been shown to reduce comple- 
ment activation and the subsequent inflammatory response [16]-[19]. Finally, reduction in hemodilution and hemolysis leads to lower transfusion rates, further reducing potential activation of the inflammatory response and other deleterious effects associated with transfusion in this population [20] [21].

Previous authors have demonstrated distinct advantages to use of a miniaturized bypass circuit, with documentation of lower pro-inflammatory cytokines, reduced transfusion requirements, shortened duration of ventilation and ICU stay, and reduction in deleterious neurocognitive effects [9]-[14] [19] [22]-[24]. Direct comparison with OPCABG has indicated that miniaturized circuits are comparable to OPCABG in terms of inflammatory response generated [24], and may be the desired alternative where OPCABG is not possible. Cardiopulmonary bypass has evolved greatly since its inception, with modifications and improvements in every facet of the system. Given the body of work indicating the potential benefits, as well as a growing experience demonstrating safety with these systems, it would appear that the miniaturized circuit is the next stage in the evolution of CPB.

At this center, the MCPBC system has been shown to be comparable to conventional bypass and OPCABG with regards to post-operative complications and mortality, though rates for all three modalities are low. The MCPBC system group had a non-statistically significant decrease in transfusion requirement compared to conventional bypass and OPCABG, though changes in preoperative vs. postoperative PLT and Hct were not statistically significant. Though these changes did not reach significance, the rates of transfusion and changes in PLT and Hct were certainly not worse in the MCPBC group. Based on our observations, a mini-cardiopulmonary bypass circuit provides a safe alternative to conventional cardiopulmonary bypass or OPCABG within this population.

As noted above, a portion of the patients included here underwent CABG with CPB support, but without crossclamping and arresting the heart (BHOP). The use of BHOP technique has been debated in the literature, and our limited number did not allow specific subgroup analysis of this population here. It should be noted, however, that our outcomes in this small subgroup compared favorably to patients receiving OPCABG, and that this technique remains a good option for patients who require some measure of support but for whom the risks of full arrest and crossclamping are high. The MCPBC system used here functioned well in all cases where a BHOP technique was used, and there were no issues with this implementation.

While our observations were interesting, our study had some important limitations. Our patients were not randomized into different groups; the decision regarding which method to use was up to the individual surgeon. This lack of randomization led to higher burden of disease individuals being placed in the OPACBG group, as evidenced by their higher rate of pre-existing renal failure and preoperative IABP use. The effects of this skewed distribution is likely seen in the higher than expected transfusion rates within the OPCABG group, though this is purely speculative as our study was not powered to examine this directly. Finally, the small cohort studied here makes more robust statistical analyses of the chosen end points impossible and increases the risk of type II error.

One of the previously postulated concerns regarding the implementation of miniaturized CPB systems is their applicability to a wide range of cardiac procedures. Previous systems have been marketed for simple procedures, primarily isolated CABG. The NovoSci Ready System 200 described here is unique in that it is the first miniaturized system to be specifically designed to handle all cardiac procedures. Though not included in our analysis due to low number and inability to compare directly to OPCABG, we performed several complex cardiac cases using this system without incident and with outcomes that compared favorably to our standard CPB setup. This favorable experience across a wide range of procedures has led to our adoption of a modified miniaturized system for $100 \%$ of on-pump cases at our facility.

Though the NovoSci system described here can be utilized for the majority of cardiac procedures, it does have some notable drawbacks. The system may be more demanding of the perfusionist, and currently these systems are more costly than a typical CPB circuit, presenting obstacles to their widespread adoption. In order to address the cost issues, as well as the additional challenges to the perfusionist, we have attempted to modify our standard CPB circuit to incorporate the benefits of the MCPBC system. Currently, we are using the Medtronic standard circuit, which is Trillium coated with an integrated open venous reservoir, arterial filter, and affinity oxygenator. We use the Sorin Revolution for our centrifugal pump and have shortened the lines in our circuit. These shorter lines, as well as the routine use of Retrograde Autologous Priming (RAP) have facilitated the reduction of hemodilution by lowering the prime volume to around $200 \mathrm{ml}$ for most patients. In addition, we have stopped the routine use of the cardiotomy suction in an effort to further reduce pro-inflammatory elements.

These changes to the standard pump setup are relatively simple, and easily implemented in the vast majority 
of cardiac surgery practices. We believe that these small modifications achieve the best of both the miniaturized and conventional circuits and encourage our colleagues to consider similar changes to their standard pump setup.

\section{Conclusion}

The MCPBC system tested here is comparable to conventional bypass and OPCABG in terms of postoperative complications and mortality, and may reduce transfusion amounts. A mini-cardiopulmonary bypass circuit provides a safe alternative to conventional bypass techniques, and can be easily implemented to most practices.

\section{References}

[1] Gibbon Jr., J.H. (1954) Application of a Mechanical Heart and Lung Apparatus to Cardiac Surgery. Minnesota Medicine, 37, 171-185.

[2] Edwards, F.H., Clark, R.E. and Schwartz, M. (1994) Coronary Artery Bypass Grafting: The Society of Thoracic Surgeons National Database Experience. The Annals of Thoracic Surgery, 57, 12-19.

http://dx.doi.org/10.1016/0003-4975(94)90358-1

[3] Fitzgibbon, G.M., Kafka, H.P., Leach, A.J., Keon, W.J., Hooper, G.D. and Burton, J.R. (1996) Coronary Bypass Graft Fate and Patient Outcome: Angiographic Follow-Up of 5,065 Grafts Related to Survival and Reoperation in 1,388 Patients during 25 Years. Journal of the American College of Cardiology, 28, 616-626.

http://dx.doi.org/10.1016/0735-1097(96)00206-9

[4] Liebold, A., Keyl, C. and Birnbaum, D.E. (1999) The Heart Produces but the Lungs Consume Proinflammatory Cytokines Following Cardiopulmonary Bypass. European Journal Cardio-Thoracic Surgery, 15, 340-345. http://dx.doi.org/10.1016/S1010-7940(99)00038-X

[5] Wendel, H.P. and Ziemer, G. (1999) Coating-Techniques to Improve the Hemocompatibility of Artificial Devices Used for Extracorporeal Circulation. European Journal Cardio-Thoracic Surgery, 16, 342-350. http://dx.doi.org/10.1016/S1010-7940(99)00210-9

[6] Kirklin, J.K., Westaby, S., Blackstone, E.H., Kirklin, J.W., Chenoweth, D.E. and Pacifico, A.D. (1983) Complement and the Damaging Effects of Cardiopulmonary Bypass. The Journal of Thoracic and Cardiovascular Surgery, 86, 845857.

[7] Paparella, D., Yau, T.M. and Young, E. (2002) Cardiopulmonary Bypass Induced Inflammation: Pathophysiology and Treatment. An Update. European Journal Cardio-Thoracic Surgery, 21, 232-244. http://dx.doi.org/10.1016/S1010-7940(01)01099-5

[8] Puskas, J.D. and Steele, M. (2007) Would You Like Some Cardiopulmonary Bypass with your Coronary Revascularization? Circulation, 116, 1756-1758. http://dx.doi.org/10.1161/CIRCULATIONAHA.107.733089

[9] Wiesenack, C., Liebold, A., Philipp, A., Ritzka, M., Koppenberg, J., Birnbaum, D.E. and Keyl, C. (2004) Four Years' Experience with a Miniaturized Extracorporeal Circulation System and Its Influence on Clinical Outcome. Artificial Organs, 28, 1082-1088. http://dx.doi.org/10.1111/j.1525-1594.2004.00030.x

[10] Sakwa, M.P., Emery, R.W., Shannon, F.L., Altshuler, J.M., Mitchell, D., Zwada, D. and Holter, A.R. (2009) Coronary Artery Bypass Grafting with a Minimized Cardiopulmonary Bypass Circuit: A Prospective, Randomized Trial. The Journal of Thoracic and Cardiovascular Surgery, 137, 481-485. http://dx.doi.org/10.1016/j.jtcvs.2008.08.057

[11] Remadi, J.P., Marticho, P., Butoi, I., Rakotoarivelo, Z., Trojette, F., Benamar, A., Beloucif, S., Foure, D. and Poulain, H.J. (2004) Clinical Experience with the Mini-Extracorporeal Circulation System: An Evolution or a Revolution? The Annals of Thoracic Surgery, 77, 2172-2175. http://dx.doi.org/10.1016/S0003-4975(03)00977-9

[12] Liebold, A., Khosravi, A., Westphal, B., Skrabal, C., Choi, Y.H., Stamm, C., Kaminski, A., Alms, A., Birken, T., Zurakowski, D. and Steinhoff, G. (2006) Effect of Closed Minimized Cardiopulmonary Bypass on Cerebral Tissue Oxygenation and Microembolization. The Journal of Thoracic and Cardiovascular Surgery, 131, 268-276. http://dx.doi.org/10.1016/j.jtcvs.2005.09.023

[13] Abdel-Rahman, U., Ozaslan, F., Risteski, P.S., Martens, S., Moritz, A., Al Daraghmeh, A., Keller, H. and WimmerGreinecker, G. (2005) Initial Experience with a Minimized Extracorporeal Bypass System: Is There a Clinical Benefit? The Annals of Thoracic Surgery, 80, 238-243. http://dx.doi.org/10.1016/j.athoracsur.2005.02.032

[14] Beghi, C., Nicolini, F., Agostinelli, A., Borrello, B., Budillon, A.M., Bacciottini, F., Friggeri, M., Costa, A., Belli, L., Battistelli, L. and Gherli, T. (2006) Mini-Cardiopulmonary Bypass System: Results of a Prospective Randomized Study. The Annals of Thoracic Surgery, 81, 1396-400. http://dx.doi.org/10.1016/j.athoracsur.2005.10.015

[15] Balachandran, S., Cross, M.H., Karthikeyan, S., Mulpur, A., Hansbro, S.D. and Hobson, P. (2002) Retrograde Autologous Priming of the Cardiopulmonary Bypass Circuit Reduces Blood Transfusion after Coronary Artery Surgery. 
The Annals of Thoracic Surgery, 73, 1912-1918. http://dx.doi.org/10.1016/S0003-4975(02)03513-0

[16] Hsu, L.C. (1997) Biocompatibility in Cardiopulmonary Bypass. Journal of Cardiothoracic and Vascular Anesthesia, 11, 376-382. http://dx.doi.org/10.1016/S1053-0770(97)90108-7

[17] Palatianos, G.M., Foroulis, C.N., Vassili, M.I., Astras, G., Triantafillou, K., Papadakis, E., Lidoriki, A.A., Iliopoulou, E. and Melissari, E.N. (2003) A Prospective, Double-Blind Study on the Efficacy of the Bioline Surface-Heparinized Extracorporeal Perfusion Circuit. The Annals of Thoracic Surgery, 76, 129-135. http://dx.doi.org/10.1016/S0003-4975(03)00338-2

[18] Ovrum, E., Mollnes, T.E., Fosse, E., Holen, E.A., Tangen, G., Abdelnoor, M., Ringdal, M.A., Oystese, R. and Venge, P. (1995) Complement and Granulocyte Activation in Two Different Types of Heparinized Extracorporeal Circuits. The Journal of Thoracic and Cardiovascular Surgery, 110, 1623-1632. http://dx.doi.org/10.1016/S0022-5223(95)70023-4

[19] Fromes, Y., Gaillard, D., Ponzio, O., Chauffert, M., Gerhardt, M.F., Deleuze, P. and Bical, O.M. (2002) Reduction of the Inflammatory Response Following Coronary Bypass Grafting with Total Minimal Extracorporeal Circulation. European Journal Cardio-Thoracic Surgery, 22, 527-533. http://dx.doi.org/10.1016/S1010-7940(02)00372-X

[20] Koch, C.G., Li, L., Duncan, A.I., Mihaljevic, T., Cosgrove, D.M., Loop, F.D., Starr, N.J. and Blackstone, E.H. (2006) Morbidity and Mortality Risk Associated with Red Blood Cell and Blood-Component Transfusion in Isolated Coronary Artery Bypass Grafting. Critical Care Medicine, 34, 1608-1616. http://dx.doi.org/10.1097/01.CCM.0000217920.48559.D8

[21] Koch, C.G., Li, L., Duncan, A.I., Mihaljevic, T., Loop, F.D., Starr, N.J. and Blackstone, E.H. (2006) Transfusion in Coronary Artery Bypass Grafting Is Associated with Reduced Long-Term Survival. The Annals of Thoracic Surgery, 81, 1650-1657. http://dx.doi.org/10.1016/j.athoracsur.2005.12.037

[22] Fromes, Y., Gaillard, D., Ponzio, O., Chauffert, M., Gerhardt, M.F., Deleuze, P. and Bical, O.M. (2002) Reduction of the Inflammatory Response Following Coronary Bypass Grafting with Total Minimal Extracorporeal Circulation. European Journal Cardio-Thoracic Surgery, 22, 527-533. http://dx.doi.org/10.1016/S1010-7940(02)00372-X

[23] Harling, L., Warren, O.J., Martin, A., Kemp, P.R., Evans, P.C., Darzi, A. and Athanasiou, T. (2011) Do Miniaturized Extracorporeal Circuits Confer Significant Clinical Benefit without Compromising Safety? A Meta-Analysis of Randomized Controlled Trials. ASAIO Journal, 57, 141-151. http://dx.doi.org/10.1097/MAT.0b013e318209d63b

[24] Formica, F., Broccolo, F., Martino, A., Sciucchetti, J., Giordano, V., Avalli, L., Radaelli, G., Ferro, O., Corti, F., Cocuzza, C. and Paolini, G. (2009) Myocardial Revascularization with Miniaturized Extracorporeal Circulation versus Off Pump: Evaluation of Systemic and Myocardial Inflammatory Response in a Prospective Randomized Study. The Journal of Thoracic and Cardiovascular Surgery, 137, 1206-1212. http://dx.doi.org/10.1016/j.jtcvs.2008.09.074 
Scientific Research Publishing (SCIRP) is one of the largest Open Access journal publishers. It is currently publishing more than 200 open access, online, peer-reviewed journals covering a wide range of academic disciplines. SCIRP serves the worldwide academic communities and contributes to the progress and application of science with its publication.

Other selected journals from SCIRP are listed as below. Submit your manuscript to us via either submit@scirp.org or Online Submission Portal.
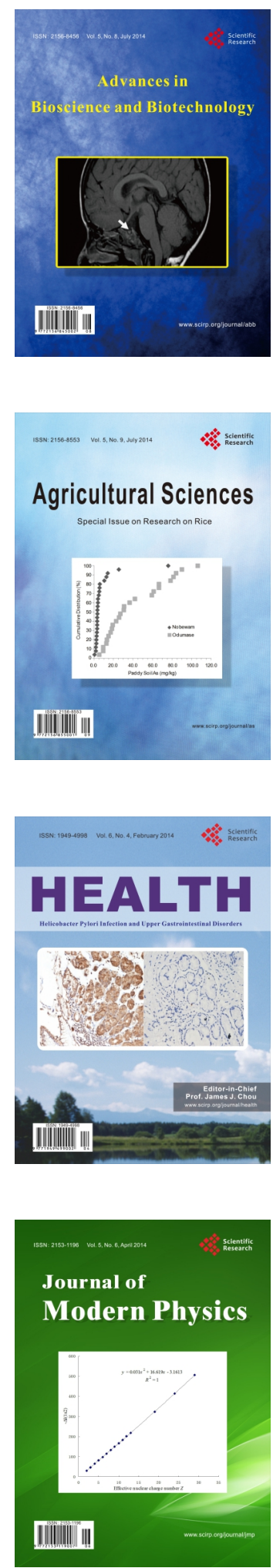
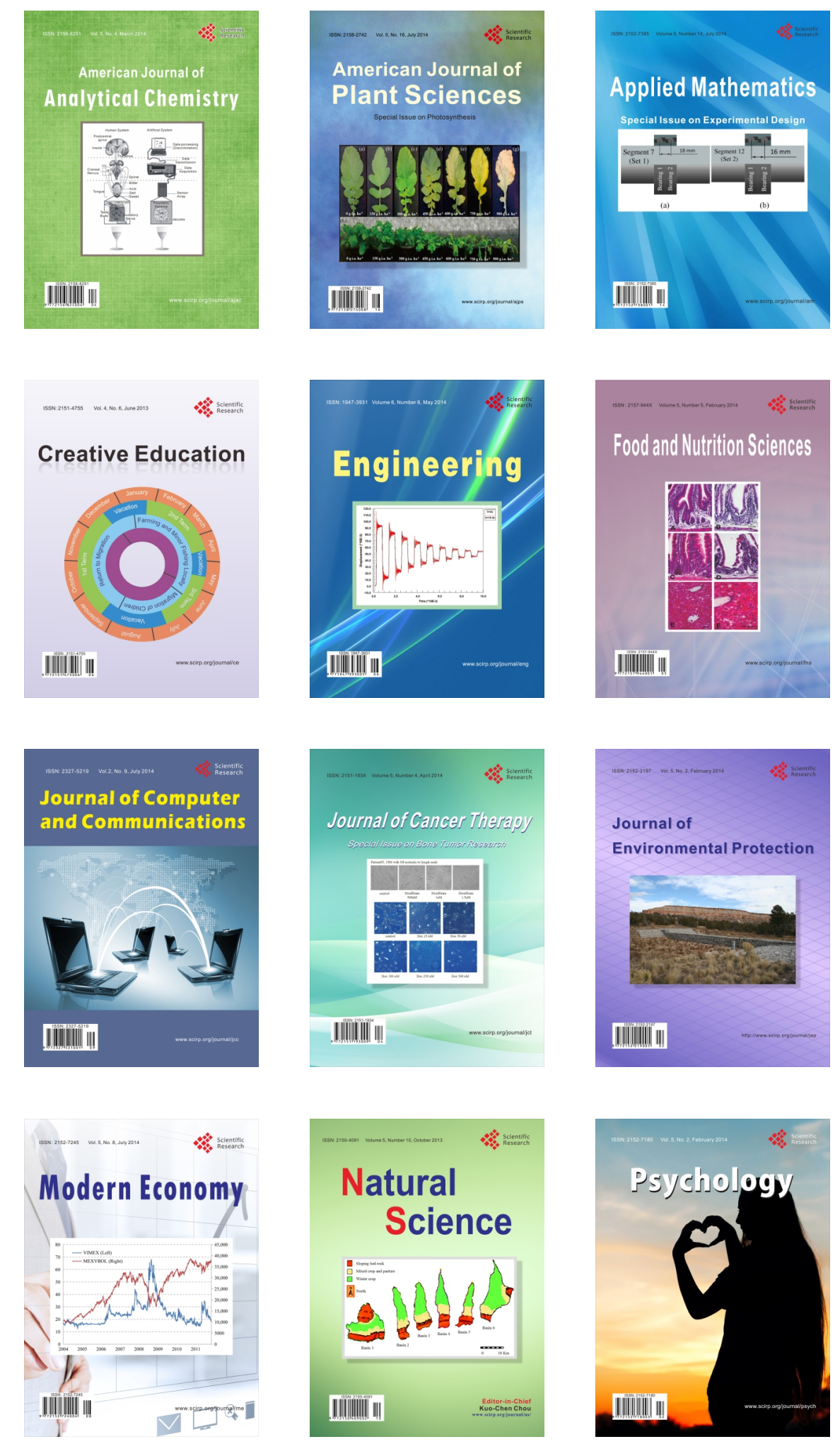